\title{
Multi-Machine Stability Using Dynamic Inversion Technique
}

\author{
Abha Tripathi ${ }^{1}$, K. Uma Rao ${ }^{2}$, L. Venkatesha ${ }^{3}$ \\ ${ }^{1}$ Departement of Electrical and Electronics Engineering, PES Institute of Technology \\ ${ }^{2}$ Departement of Electrical \& Electronics Engineering RV College of Engineering \\ ${ }^{3}$ Department of Electrical \& Electronics Engineering, BMS College of Engineering
}

\begin{tabular}{l} 
Article Info \\
\hline Article history: \\
Received Dec 20, 2016 \\
Revised May 12, 2017 \\
Accepted Jun 6, 2017 \\
\hline Keyword: \\
Dynamic inversion \\
Thyristor controlled series \\
Compensation \\
Multi-Machine \\
Stability \\
Non-linear technique \\
\hline
\end{tabular}

\begin{abstract}
Stability studies of multi machine system are a major concern to power system engineers due to the increasing complexity involved. This paper deals with the application of a nonlinear technique called Dynamic Inversion, to TCSC for the improvement of stability of multi-machine system. The transient stability studies for various cases: without any controller, with $75 \%$ line compensation and with Dynamic Inversion technique, are compared. The critical clearing time as well as the maximum loading ability is also discussed. The result for the nonlinear controller is found to be better than all the other cases.
\end{abstract}

Copyright $(2017$ Institute of Advanced Engineering and Science. All rights reserved.

Corresponding Author:

Abha Tripathi,

Departement of Electrical and Electronics Engineering,

PES Institute of Technology,

100 Feet Outer Ring Road, Banashankari III Stage, Bangalore, 560085, India.

Email: abhatripathi@gmail.com

\section{INTRODUCTION}

An important issue in multi-machine systems is the choice of location of various devices. It is known that multi-machine systems, normally, split into two groups initially, whenever the system becomes unstable [1],[2]. Consequently there is a critical cut-set which separates the system into these two groups. Locating series devices in these lines will strengthen them and thus aid in improving stability. The compensating devices can therefore be located in lines which form the critical cut-set for critical contingencies [3]. Another key issue in multi-machine systems is the choice of control signals. It is essential for robust operation and control, that each device can be controlled by signals that are locally measurable and require minimum telemetry from other areas.

Trajectory sensitivity analysis (TSA) was used to measure the transient stability condition of the system in [4]. The TCSC was modelled by a variable capacitor, the value of which changes with the firing angle. It was shown that TSA could be used in the design of the controller. The optimal locations of the Thyristor Controlled Series Compensation (TCSC) - controller for different fault conditions could also be identified with the help of TSA.

In order to improve the Transient Stability of a 9 Bus System with Fixed Compensation on Various Lines and Optimal Location was investigated using trajectory sensitivity analysis in [5]. A fuzzy controlled TCSC device was used and the results highlighted the effectiveness of the application of a TCSC in improving the transient stability of a multi machine power system. In [6], the effect of STATCOM for improving the stability of the multi machine power system was investigated. The STATCOM was used to control power flow of power system by injecting appropriate reactive power during dynamic state. 
Simulation results showed that STATCOM not only considerably improved transient stability but also compensated the reactive power in steady state. This was implemented on a three machine nine bus, power system.

A novel hybrid power flow controller (HPFC) topology for Flexible AC Transmission System (FACTS) was proposed in [7]. The key benefit of the new topology was that it fully utilized existing equipment. The MATLAB/ SIMULINK models of three different configurations of HPFC had been investigated for their different characteristics, by incorporating them in the multi machine system.

A model for assessment of transient stability of power system was developed in [8]. This was tested for a single machine infinite bus system as well as multi-machine system. An Unified Power Flow Controller (UPFC) was demonstrated in [9] to improve the damping of oscillations as well as increase the critical clearing time for multi-machine system. In this paper a non-linear technique called Dynamic Inversion has been implemented through TCSC to improve the various aspects of stability issues in multi-machine system, such as transient stability, critical clearing time, loading, etc.

\section{DYNAMIC INVERSION TECHNIQUE}

Dynamic Inversion is a technique to track the desired output by forcing the error to zero [10]. Let the state dynamics be defined as:

$$
\dot{x}=f(x)+[g(x)] u
$$

where $x$ is the state vector, $f(x)$ is the dynamics without the control and $g(x)$ is the state dynamics with the control $u$. If the output vector is identical to the state vector, then equation (1) may be written as follows:

$$
\dot{y}=f(x)+[g(x)] u
$$

If $y_{\text {desired }}$ is the desired output and the actual output is $y$, error can be defined as

$$
e=y-y_{\text {desired }}
$$

The error can be forced to approach zero by using the below given equation:

$$
\dot{e}+k e=0
$$

where $k>0$ and $\dot{e}$ is the derivative of error and is given by

$$
\dot{e}=\dot{y}-\dot{y}_{\text {desired }}
$$

The solution of equation (5) is

$$
e=e^{-k t} e_{0}
$$

where $e_{0}$ is the initial error. From equation (6), we can observe that the error will tend to zero as time $t$ tends to infinity. Using the value of error and the derivative of error from equations (3) and (5) and substituting the same in equation (4), we get and taking $\dot{y}_{\text {desired }}=0$ as the desired output is fixed.

$$
f(x)+[g(x)] u+k\left(y-y_{\text {desired }}\right)=0
$$

Hence the controller is given by:

$$
\left.u=[g(x)]^{-1}\left\{-k\left(y-y_{\text {desired }}\right)-f(x)\right\}\right]
$$

The above controller equation and gives the value of the controllable parameter $u$ to get the desired output. $u$ is computed using equation (8) in real time. This control law can be applied to any dynamic 
system and reported in [10],[11] and has successfully been implemented in the command tracking of high performance aircraft. Dynamic Inversion technique has been applied to an SMIB and its robustness also checked in [12]-[14].

\section{FIVE BUS POWER SYSTEM WITH TWO MACHINES (TEST SYSTEM 1)}

Figure 1 shows a five bus network containing two generators and seven transmission lines [15]. The loads are in MW and MVAr and a base of 100MVA is considered. All the reactances and the half line charging admittances are mentioned in per unit. The line resistances and machine resistances are neglected. It is assumed that there is a three phase fault on bus 5 and the same is cleared without changing the system configuration.

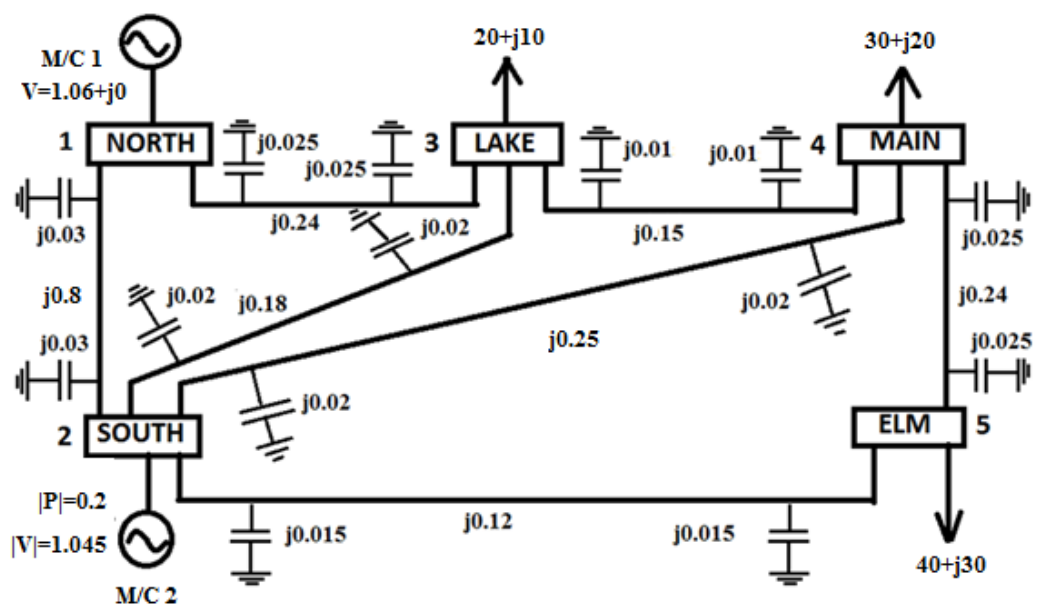

Figure 1. Multi-machine Test system

Bus 1 is considered as a slack or swing bus, bus 2 is a generator or a PV bus and buses 3, 4 and 5 are load or PQ bus. The following parameters are used: Inertia constant of the two machines are $H_{1}=50 M J / M V A$ and $H_{2}=1 M J / M V A$; Direct axis transient reactance of the first machine is $x_{d 1}^{\prime}=1 p u$ and for the second machine is $x_{d 2}^{\prime}=1.5 \mathrm{pu}$.

\subsection{Transient Stability Analysis without DI Technique}

All loads are converted to per unit on a common base of 100 MVA. Load flow analysis using Newton Raphson method was done prior to the fault and the results are as shown in Table 1.

Table 1. Load Flow Analysis

\begin{tabular}{|c|c|c|c|}
\hline Bus No. & $\begin{array}{c}\mathrm{P}_{\mathrm{G}}+\mathrm{jQ}_{\mathrm{G}} \\
(\mathrm{MW}+\mathrm{j} \mathrm{MVAr})\end{array}$ & $\begin{array}{c}\mathrm{P}_{\mathrm{L}}+\mathrm{j} \mathrm{Q}_{\mathrm{L}} \\
(\mathrm{MW}+\mathrm{jMVAr})\end{array}$ & $\begin{array}{l}\mathrm{V} \angle \theta \\
\text { (in pu) }\end{array}$ \\
\hline 1 & $70+\mathrm{j} 10.84$ & 0 & $1.06 \angle 0^{0}$ \\
\hline 2 & $20+\mathrm{j} 30.15$ & 0 & $1.045<-7.26^{0}$ \\
\hline 3 & 0 & $20+j 10$ & $1.035 \angle-6.59^{0}$ \\
\hline 4 & 0 & $30+j 20$ & $1.023<-8.66^{0}$ \\
\hline 5 & 0 & $40+\mathrm{j} 30$ & $1.017<-9.46^{0}$ \\
\hline
\end{tabular}

The loads are converted to admittances. The voltages at the various buses, current from the generators and hence the powers from the generators are calculated. The state dynamics equations are solved using Runge-Kutta $4^{\text {th }}$ order method. The four state dynamic equations for the two generators are as follows:

$$
\frac{d \delta_{1}}{d t}=\omega_{1}-\omega_{s}
$$




$$
\begin{aligned}
& \frac{d \omega_{1}}{d t}=\frac{\omega_{s}}{2 H_{1}}\left(P_{m 1}-P_{e 1}\right) \\
& \frac{d \delta_{2}}{d t}=\omega_{2}-\omega_{s} \\
& \frac{d \omega_{2}}{d t}=\frac{\omega_{s}}{2 H_{2}}\left(P_{m 2}-P_{e 2}\right)
\end{aligned}
$$

where $\delta_{1}$ and $\delta_{2}$ are the rotor angles, $\omega_{1}$ and $\omega_{2}$ are the angular frequencies of machine 1 and 2 respectively and $\omega_{s}$ is the synchronous or nominal frequency of the system.

\subsection{Transient Stability Analysis with $75 \%$ Line Compensation}

In this case it assumed that the line where TCSC will be connected is $75 \%$ compensated by a series capacitance connected to it. The line reactance now becomes 0.2 per unit instead of 0.8 pu.

\subsection{Transient Stability Analysis with DI Technique}

As depicted in Figure 2, the TCSC is present in the line connecting buses 1 and 2. The line is 50\% compensated by fixed capacitor and the TCSC reactance is varied between $0-25 \%$. The reactance of the line will change dynamically as the TCSC reactance is varied. The TCSC is operated only in the capacitive region.

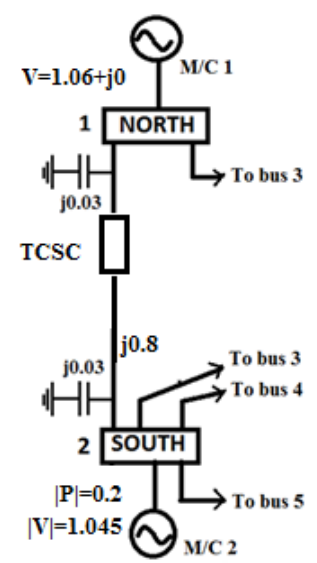

Figure 2. Part of the network where TCSC is inserted

Let $U$ be the TCSC reactance (capacitive). The elements of $\mathrm{Y}$ will change as the control varies. Since TCSC is in line 1-2, hence four elements of $Y$ that will change, will be $Y_{12}, Y_{21}, Y_{11}, Y_{22}$ and they are as given underneath:

$$
\begin{aligned}
& Y_{12}=Y_{21}=-1 /\left(j x_{12}-j U\right) \\
& Y_{11}=1 /\left(j x_{12}-j U\right)+1 / j x_{13}+y_{h l c 12}+y_{h l c 13} \\
& Y_{22}=1 /\left(j x_{12}-j U\right)+1 / j x_{23}+1 / j x_{24}+1 / j x_{25}+y_{h l c 12}+y_{h l c 23}+y_{h l c 24}+y_{h l c 25}
\end{aligned}
$$

where $x_{12}, x_{13}, x_{23}, x_{24}, x_{25}$ are the series reactances $y_{h l c 12}, y_{h l c 13}, y_{h l c 23}, y_{h l c 24}, y_{h l c 25}$ are the half line charging admittances of lines between buses 1-2, 1-3,2-3,2-4 and 2-5 respectively. As the $Y$ elements are changing, the voltages during $(k+1)^{\text {th }}$ time iteration at various buses will change 


$$
\begin{aligned}
& \bar{V}_{1}^{k+1}=-\frac{Y_{12}}{Y_{11}} \bar{V}_{2}^{k}-\frac{Y_{13}}{Y_{11}} \bar{V}_{3}^{k}-\frac{Y_{16}}{Y_{11}} \bar{E}_{1} \\
& \bar{V}_{2}^{k+1}=-\frac{Y_{21}}{Y_{22}} \bar{V}_{1}^{k+1}-\frac{Y_{23}}{Y_{22}} \bar{V}_{3}^{k}-\frac{Y_{24}}{Y_{22}} \bar{V}_{4}^{k}-\frac{Y_{25}}{Y_{22}} \bar{V}_{5}^{k}-\frac{Y_{27}}{Y_{22}} \bar{E}_{2} \\
& \bar{V}_{3}^{k+1}=-\frac{Y_{31}}{Y_{33}} \bar{V}_{1}^{k+1}-\frac{Y_{32}}{Y_{33}} \bar{V}_{2}^{k+1}-\frac{Y_{34}}{Y_{33}} \bar{V}_{4}^{k} \\
& \bar{V}_{4}^{k+1}=-\frac{Y_{41}}{Y_{44}} \bar{V}_{2}^{k+1}-\frac{Y_{43}}{Y_{44}} \bar{V}_{3}^{k+1}-\frac{Y_{45}}{Y_{44}} \bar{V}_{5}^{k} \\
& \bar{V}_{5}^{k+1}=-\frac{Y_{52}}{Y_{55}} \bar{V}_{2}^{k+1}-\frac{Y_{54}}{Y_{55}} \bar{V}_{4}^{k+1}
\end{aligned}
$$

Electrical power of first machine, during the $(k+1)^{t h}$ is given by

$$
\begin{aligned}
& P_{e 1}^{k+1}=\operatorname{Re}\left(E_{1}^{k+1} \angle \delta_{1}^{k+1}\left(\bar{I}_{1}^{k+1}\right)^{*}\right) \\
& P_{e 1}^{k+1}=\operatorname{Re}\left(E_{1}^{k+1} \angle \delta_{1}^{k+1}\left(\left(E_{1}^{k+1} \angle \delta_{1}^{k+1}-\bar{V}_{1}^{k+1}\right) / j x_{d 1}\right)^{*}\right)
\end{aligned}
$$

Using the voltage expression from equation (17),

$$
P_{e 1}^{k+1}=\operatorname{Re}\left(E_{1}^{k+1} \angle \delta_{1}^{k+1}\left(\left(\begin{array}{l}
E_{1}^{k+1} \angle \delta_{1}^{k+1}-\ldots . \\
\left.\left(-\frac{Y_{12}}{Y_{11}} \bar{V}_{2}^{k}-\frac{Y_{13}}{Y_{11}} \bar{V}_{3}^{k}-\frac{Y_{16}}{Y_{11}} \bar{E}_{1}^{k+1}\right) / j x_{d 1}\right)
\end{array}\right)\right)\right.
$$

Finally,

$$
\begin{aligned}
P_{e 1}^{k+1}= & \left|\bar{E}_{1}^{k+1}\right| \bar{V}_{2}^{k+1} \mid \sin \left(\delta_{1}^{k+1}-\phi_{2}^{k+1}\right) /\left(x_{d 1}\left(x_{12}-U\right)\left(a_{1}-1 /\left(x_{12}-U\right)\right)\right)+ \\
& \left|\bar{E}_{1}^{k+1} \| \bar{V}_{2}^{k+1}\right|\left|Y_{13}\right| \sin \left(\delta_{1}^{k+1}-\phi_{3}^{k+1}\right) /\left(x_{d 1}\left(x_{12}-U\right)\left(a_{1}-1 /\left(x_{12}-U\right)\right)\right)
\end{aligned}
$$

where $a_{1}=y_{h l c 12}+y_{h l c 13}-1 / x_{d 1}-1 / x_{13}$ and $\phi_{2}^{k+1}, \phi_{3}^{k+1}$ are the angles of voltages $\bar{V}_{2}^{k+1}$ and $\bar{V}_{3}^{k+1}$ respectively at the $(k+1)^{\text {th }}$ time iteration. Now, the four states are $\delta_{1}, \omega_{1}, \delta_{2} \omega_{2}$ and hence the state equations can be rewritten as follows:

$$
\begin{aligned}
& \dot{x}_{1}=\frac{d x_{1}}{d t}=x_{2}-\omega_{s} \\
& \dot{x}_{2}=\frac{d x_{2}}{d t}=\frac{\omega_{s}}{2 H_{1}}\left(P_{m 1}-P_{e 1}\right) \\
& \dot{x}_{3}=\frac{d x_{3}}{d t}=x_{4}-\omega_{s} \\
& \dot{x}_{4}=\frac{d x_{4}}{d t}=\frac{\omega_{s}}{2 H_{2}}\left(P_{m 2}-P_{e 2}\right)
\end{aligned}
$$


The desired output $x_{2 d}$ is to maintain the speed of the first machine, state $x_{2}$, constant, at 377 $\mathrm{rad} / \mathrm{sec}$ (or nominal frequency as $60 \mathrm{~Hz}$ ). The error $e$ is defined as

$$
e=x_{2}-x_{2 d}
$$

The derivative of error is

$$
\dot{e}=\dot{x}_{2}-\dot{x}_{2 d}
$$

The error dynamics is enforced as follows:

$$
\dot{e}+K_{1} e=0
$$

Now the solution of such an equation is given as follows:

$$
e(t)=e_{0} e^{-K_{1} t}
$$

where $K_{1}$ is a positive constant which ensures that the error tends to zero as time tends to infinity. As the desired output is fixed, its derivative is zero. Using equations (26) in equation (30), the following is obtained:

$$
\dot{e}=\frac{\omega_{s}}{2 H_{1}}\left(P_{m 1}-P_{e 1}\right)-0
$$

By enforcing error dynamics from equation (33), the following is obtained:

$$
\left(\frac{\omega_{s}}{2 H_{1}}\left(P_{m 1}-P_{e 1}\right)-0\right)+K_{1}\left(x_{2}-x_{2 d}\right)=0
$$

Using the value of the electrical power from equation (24), in equation (34), the control variable which is reactance of TCSC, is obtained as follows:

$$
\begin{aligned}
& U=\left(P_{m 1}+2 K_{1} H_{1}\left(x_{2}-x_{2 d}\right) / \omega_{s}-\left|\bar{E}_{1} \| \bar{V}_{2}\right| \sin \left(\delta_{1}-\phi_{2}\right) / x_{d 1}^{\prime}\right) /\left(\left|\bar{E}_{1}\right|\left|\bar{V}_{3}\right|\left|Y_{13}\right| \sin \left(\delta_{1}-\phi_{3}\right) / x_{d 1}^{\prime}-\right. \\
& \left(P_{m 1}+2 K_{1} H_{1}\left(x_{2}-x_{2 d}\right) / \omega_{s}\right)\left(1 / x_{13}+y_{h l c 12}+y_{h l c 13}\right)
\end{aligned}
$$

\section{RESULTS AND DISCUSSIONS FOR $1^{\text {st }}$ TEST SYSTEM}

There are two case studies done and the results for all the cases are explained in detail in the following sub - sections.

\subsection{Case 1: When fault clearing time is 0.36 second}

It is assumed that there is a $3 \phi$ symmetrical fault at bus 5 and the same is cleared after 0.32 seconds without disturbing the system configuration. The oscillations of the rotor angle and speed of machine 2 are observed. The system is simulated and stability with and without DI technique is observed. The results are given underneath:

\subsubsection{Without DI Technique}

Figure 3 shows the variation of the delta of second machine and it is clear that the system is becoming unstable. The variation of speed of the second machine is depicted in Figure 4. The system is unstable as it is evident from this plot. 


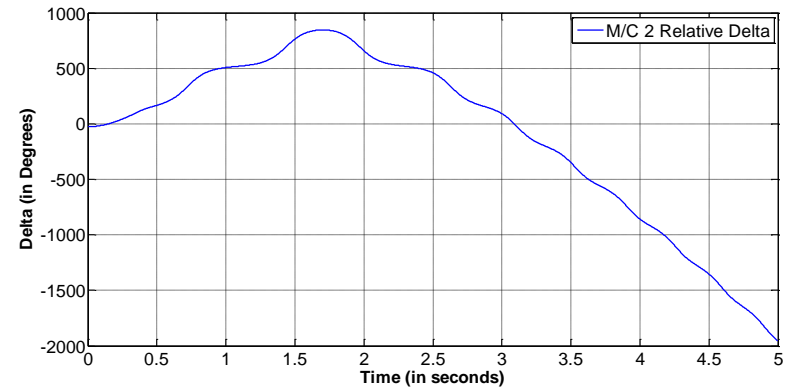

Figure 3. Delta Variation without DI Technique

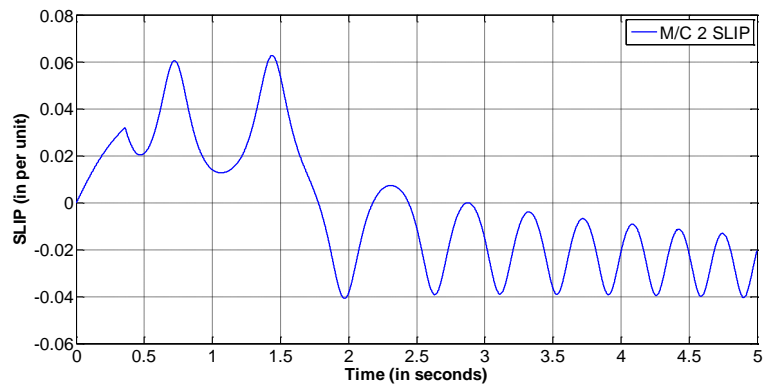

Figure 4. Slip variation without DI

\subsubsection{With $75 \%$ Line Compensation}

The delta variation is shown in Figure 5. The system stability is lost. The rotor angle keeps increasing. The slip variation with $75 \%$ line compensation is shown in Figure 6. The slip increases with time and the system becomes unstable.

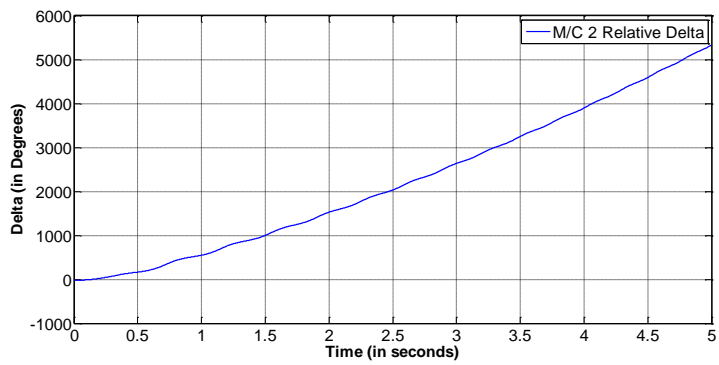

Figure 5. Delta Variation with 75\% Line Compensation

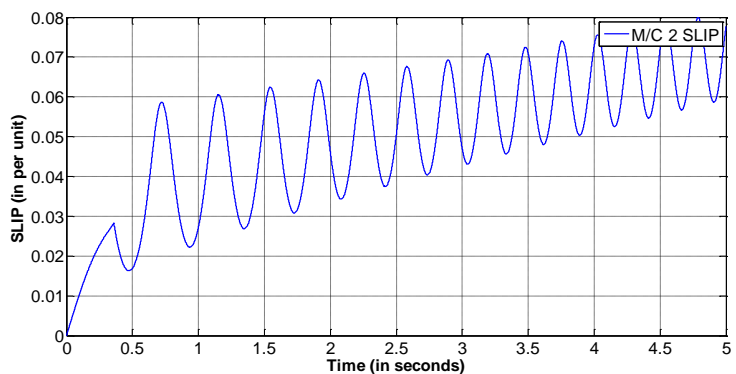

Figure 6. Slip Variation with 75\% Line Compensation 


\subsubsection{With DI Technique}

The delta of the second machine is depicted in Figure 7. With DI technique the damping of the delta improves and the system tends towards stability. The speed of machine 2 is plotted in Figure 8 . From the graph it is very clear that the damping has improved. The reactance of the TCSC is changing to keep up with desired results and the plot of the same is shown in Figure 9.

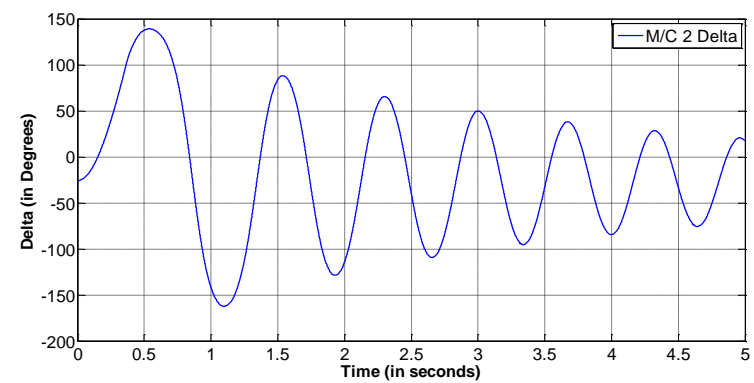

Figure 7. Delta Variation with DI technique

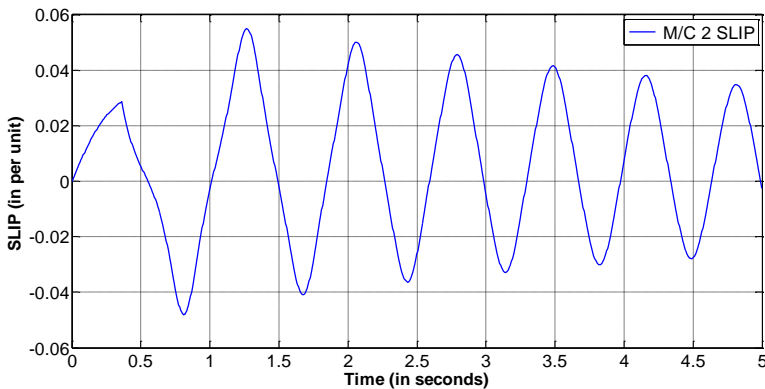

Figure 8. Speed Variation with DI Technique

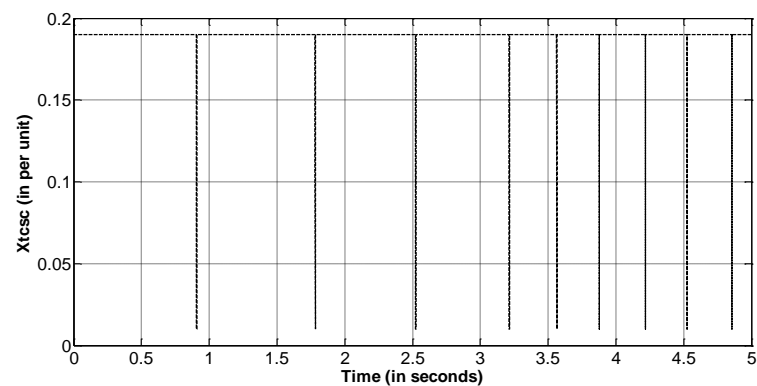

Figure 9. TCSC Reactance Variation

\subsection{Case 2: Critical Clearing Time and Maximum loading at buses}

With the load fixed at the initial values (prior to the fault), a $3 \phi$ symmetrical fault at bus 5 was assumed. The fault clearing time was increased to obtain the critical clearing time. Next, for the same nature of fault at bus 5 and fault clearing time fixed at $0.3 \mathrm{sec}$, the loading was increased at various buses. This way the maximum loading possible at all load buses, without DI technique, with $75 \%$ line compensation and with DI technique, was tabulated. The same is given in Table 2. 
Table 2. CCT and Maximum Loading

\begin{tabular}{cccc}
\hline Attribute & Without TCSC & With 75\% Compensation & With TCSC \\
\hline Critical Clearing time(in sec) & $0.315 \mathrm{sec}$ & $0.338 \mathrm{sec}$ & $0.36 \mathrm{sec}$ \\
Maximum Loading at bus 3 & $40 \mathrm{MW}$ & $75 \mathrm{MW}$ & $84 \mathrm{MW}$ \\
Maximum Loading at bus 4 & $40 \mathrm{MW}$ & $82 \mathrm{MW}$ & $95 \mathrm{MW}$ \\
Maximum loading at bus 5 & $55 \mathrm{MW}$ & $85 \mathrm{MW}$ & $96 \mathrm{MW}$ \\
\hline
\end{tabular}

\section{SECOND TEST SYSTEM: THREE MACHINE 5 BUS POWER SYSTEM}

The same power system as depicted in figure 1 is considered. The only difference is that a third machine is considered at bus 3 and that that bus is considered to be a PV bus. The active power being fixed at $0.1 \mathrm{pu}$ and the magnitude of the voltage at $1.02 \mathrm{pu}$. The resistance of the lines is neglected. As mentioned earlier, the values of the reactances are in per unit. Apart from the four state equations mentioned before for 2 machines system, there are two more state equations for the third machine which are as follows:

$$
\begin{aligned}
& \frac{d \delta_{3}}{d t}=\omega_{3}-\omega_{0} \\
& \frac{d \omega_{3}}{d t}=\frac{\omega_{s}}{2 H_{3}}\left(P_{m 3}-P_{e 3}\right)
\end{aligned}
$$

\subsection{Without DI Technique}

The load flow analysis is done and the various results are tabulated in Table 3. The fault is assumed to be at bus 5 and the same is rectified without affecting system configuration.

Table 3. Load Flow Analysis Results

\begin{tabular}{cccccc}
\hline $\begin{array}{c}\text { Bus } \\
\text { No. }\end{array}$ & $\begin{array}{c}\mathrm{P}_{\mathrm{G}} \\
\text { (in MW) }\end{array}$ & $\begin{array}{c}\mathrm{Q}_{\mathrm{G}} \\
\text { (in MVAr) }\end{array}$ & $\begin{array}{c}\mathrm{P}_{\mathrm{L}} \\
\text { (in MW) }\end{array}$ & $\begin{array}{c}\mathrm{Q}_{\mathrm{L}} \\
\text { (in MVAr) }\end{array}$ & $\begin{array}{c}\mathrm{V} \angle \theta \\
\text { (in pu) }\end{array}$ \\
\hline 1 & 40 & 14.85 & 0 & 0 & $1.06 \angle 0^{0}$ \\
2 & 20 & 44 & 0 & 0 & $1.045 \angle-4.71^{0}$ \\
3 & 10 & -31.98 & 0 & 0 & $1.02 \angle-3.65^{0}$ \\
4 & 0 & 0 & 30 & 20 & $1.015 \angle-5.94^{0}$ \\
5 & 0 & 0 & 40 & 30 & $1.014 \angle-6.86^{0}$ \\
\hline
\end{tabular}

\subsection{Analysis with $75 \%$ Line Compensation}

The line connected between buses 2 and 4 is $75 \%$ compensated and hence the new reactance of the line becomes half of 0.23 per unit.

\subsection{Analysis with DI Technique}

DI technique is realized through the TCSC which is placed as depicted in Figure 10.

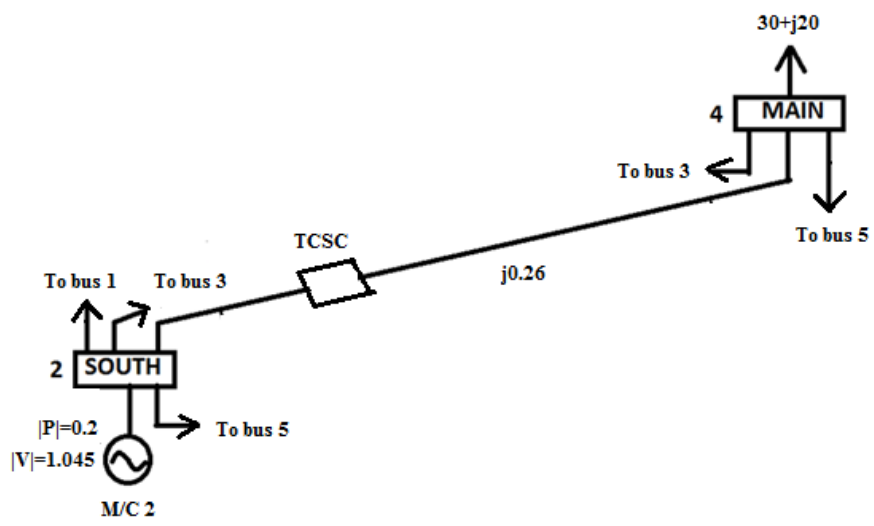

Figure 10. Part of the network where TCSC is present 
TCSC is assumed to be present in line connecting buses 2 and 4. Therefore the reactance of the line will change dynamically as the TCSC reactance is varied. $U$ is the TCSC reactance (capacitive) and some of the elements of Y will change accordingly. Since TCSC is in line $2-4$, hence four elements of $Y$ that will change will be $Y_{24}, Y_{42}, Y_{44}$ and $Y_{22}$ and they are as given underneath:

$$
\begin{aligned}
Y_{42}= & Y_{24}=-1 /\left(j x_{24}-j U\right) \\
Y_{44}= & 1 /\left(j x_{24}-j U\right)+1 / j x_{43}+1 / j x_{45}+y_{h l c 24}+y_{h l c 43}+y_{h l c 45} \\
Y_{22}= & 1 /\left(j x_{24}-j U\right)+1 / j x_{d 2}^{\prime}+1 / j x_{21}+1 / j x_{23}+\ldots \\
& 1 / j x_{25}+y_{h l c 21}+y_{h l c 23}+y_{h l c 24}+y_{h l c 25}
\end{aligned}
$$

where $x_{21}, x_{23}, x_{24}, x_{25}$ are the series reactances $y_{h l c 21}, y_{h l c 23}, y_{h l c 24}, y_{h l c 25}$ are the half line charging admittances of lines between buses $2-1,2-3,2-4$ and 2-5 respectively. The desired output $x_{4 d}$ is to maintain the speed of the second machine, state $x_{4}$, constant, at $377 \mathrm{rad} / \mathrm{sec}$ (or nominal frequency as $60 \mathrm{~Hz}$ ). Electrical power of second machine, during the $(k+1)^{t h}$ is given by

$$
\begin{aligned}
& P_{e 2}=E_{2}^{k+1} \angle \delta_{2}\left(\bar{I}_{2}^{k+1}\right)^{*} \\
& P_{e 2}=E_{2}^{k+1} \angle \delta_{2}\left(\left(E_{2}^{k+1} \angle \delta_{2}-\bar{V}_{2}^{k+1}\right) / j x_{d 2}\right)^{*}
\end{aligned}
$$

Using the voltage expression from equation (17),

$$
P_{e 2}=E_{2}^{k+1} \angle \delta_{2}\left(\left(E_{2}^{k+1} \angle \delta_{2}-\left(-\frac{Y_{21}}{Y_{22}} \bar{V}_{1}^{k+1}-\frac{Y_{23}}{Y_{22}} \bar{V}_{3}^{k}-\frac{Y_{24}}{Y_{22}} \bar{V}_{4}^{k}-\frac{Y_{25}}{Y_{22}} \bar{V}_{5}^{k}-\frac{Y_{27}}{Y_{22}} \bar{E}_{2}^{k+1}\right)\right) / j x d_{2}\right)^{*}
$$

Finally,

$$
\begin{aligned}
P_{e 2}= & \frac{\left|\bar{E}_{2}^{k+1}\right|\left|\bar{V}_{1}^{k+1}\right|\left|Y_{12}\right| \sin \left(\delta_{2}-\phi_{1}\right)}{\left(x_{d 2}\left(a_{2}-1 /\left(x_{24}-U\right)\right)\right)}+\frac{\left|\bar{E}_{2}^{k+1}\right|\left|\bar{V}_{3}^{k+1}\right|\left|Y_{23}\right| \sin \left(\delta_{2}-\phi_{3}\right)}{\left(x_{d 2}\left(a_{2}-1 /\left(x_{24}-U\right)\right)\right)}+\frac{\left|\bar{E}_{2}^{k+1}\right|\left|\bar{V}_{4}^{k+1}\right|\left|Y_{24}\right| \sin \left(\delta_{2}-\phi_{4}\right)}{\left(x_{d 2}\left(x_{24}-U\right)\left(a_{2}-1 /\left(x_{24}-U\right)\right)\right)} \\
& +\frac{\left|\bar{E}_{2}^{k+1}\right| \bar{V}_{5}^{k+1}|| Y_{25} \mid \sin \left(\delta_{2}-\phi_{5}\right)}{\left(x_{d 2}\left(a_{2}-1 /\left(x_{24}-U\right)\right)\right)}
\end{aligned}
$$

where

$$
\begin{aligned}
a_{2}= & y_{h l c 21}+y_{h l c 23}+y_{h l c 24}+y_{h l c 15}-1 / x_{d 2} \ldots . . \\
& -1 / x_{21}-1 / x_{23}-1 / x_{25}
\end{aligned}
$$

and $\phi_{1}, \phi_{3}, \phi_{4}, \phi_{5}$ are the angles of voltages $\bar{V}_{2}^{k+1}, \bar{V}_{3}^{k+1}, \bar{V}_{4}^{k+1}$ and $\bar{V}_{5}^{k+1}$ respectively. The error $e$ is defined as

$$
e=x_{4}-x_{4 d}
$$

The derivative of error is

$$
\dot{e}=\dot{x}_{4}-\dot{x}_{4 d}
$$

As the desired output is fixed, then its derivative is zero. Using this concept and the equation (45), 


$$
\begin{aligned}
& \dot{e}=\frac{\omega_{s}}{2 H_{2}}\left(P_{m 2}-P_{e 2}\right)-0 \\
& \left(\frac{\omega_{s}}{2 H_{2}}\left(P_{m 2}-P_{e 2}\right)-0\right)+K_{2}\left(x_{4}-x_{4 d}\right)=0
\end{aligned}
$$

where $K_{2}$ is a positive real constant. Using the value of the electrical power from equation (44), in equation (40), we get the control variable which is reactance of TCSC as follows:

$$
\begin{aligned}
U= & \frac{\left|\bar{E}_{2}^{k+1}\right| \bar{V}_{1}^{k+1}|| Y_{12} \mid \sin \left(\delta_{2}-\phi_{1}\right)}{x_{d 2}}+\frac{\left|\bar{E}_{2}^{k+1}\right| \bar{V}_{2}^{k+1}|| Y_{23} \mid \sin \left(\delta_{2}-\phi_{3}\right)}{x_{d 2}}+ \\
& \left.\frac{\left|\bar{E}_{2}^{k+1}\right|\left|\bar{V}_{5}^{k+1}\right|\left|Y_{25}\right| \sin \left(\delta_{2}-\phi_{5}\right)}{x_{d 2}}+P_{m 2}+2 K H_{2}\left(x_{4}-x_{4 d}\right) / \omega_{s}\right) / \\
& \left(\begin{array}{c}
\frac{\left|\bar{E}_{2}^{k+1}\right| \bar{V}_{1}^{k+1}|| Y_{12} \mid \sin \left(\delta_{2}-\phi_{1}\right)}{x_{d 2}}+\frac{\left|\bar{E}_{2}^{k+1}\right| \bar{V}_{2}^{k+1}|| Y_{23} \mid \sin \left(\delta_{2}-\phi_{3}\right)}{x_{d 2}}+ \\
\left.\frac{\left|\bar{E}_{2}^{k+1}\right| \bar{V}_{5}^{k+1}\left|Y_{25}\right| \sin \left(\delta_{2}-\phi_{5}\right)}{x_{d 2}}-P_{m 2}+2 K_{2} H_{2}\left(x_{4}-x_{4 d}\right) / \omega_{s}\right)
\end{array}\right)
\end{aligned}
$$

Various case studies were done which are discussed in the subsequent sub sections.

\section{RESULTS AND DISCUSSION FOR TEST SYSTEM 2}

\subsection{Case1: A $3 \phi$ fault which is cleared in $0.35 \mathrm{sec}$}

\subsubsection{Without DI Technique}

The fault clearing time is $0.35 \mathrm{sec}$ and the system is unstable. The variation of the delta withou DI technique is shown in Figure 11 The oscillations are very prominent. And finally, the system loses stability. The variation of the speed is plotted in Figure 12 and it is clear that the magnitude of the speed is having increasing magnitude.

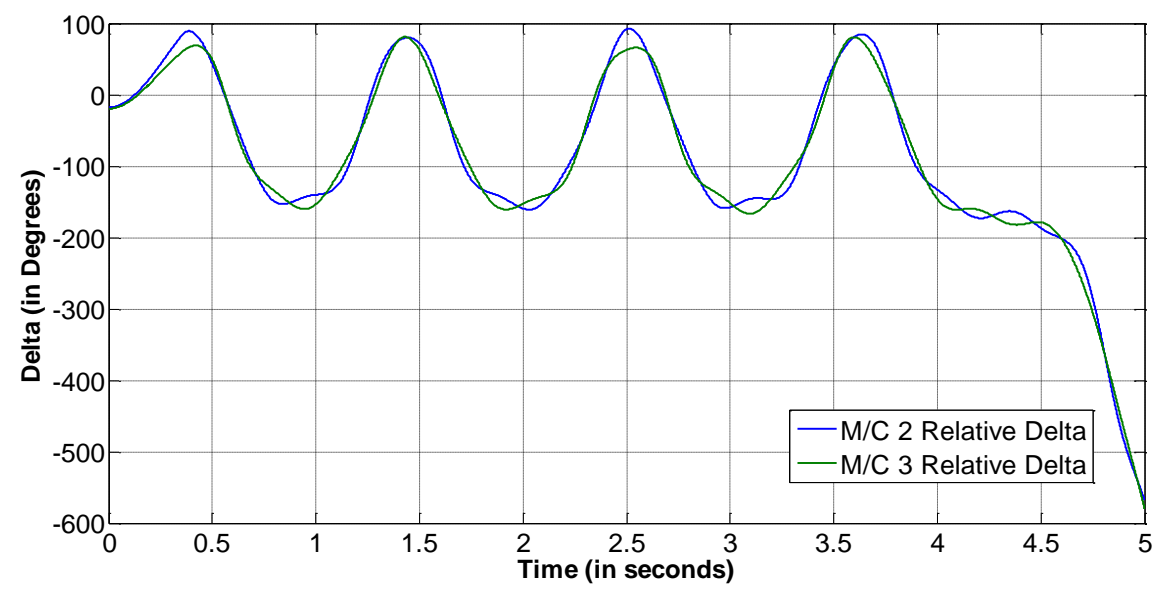

Figure 11. Delta Variation without DI 


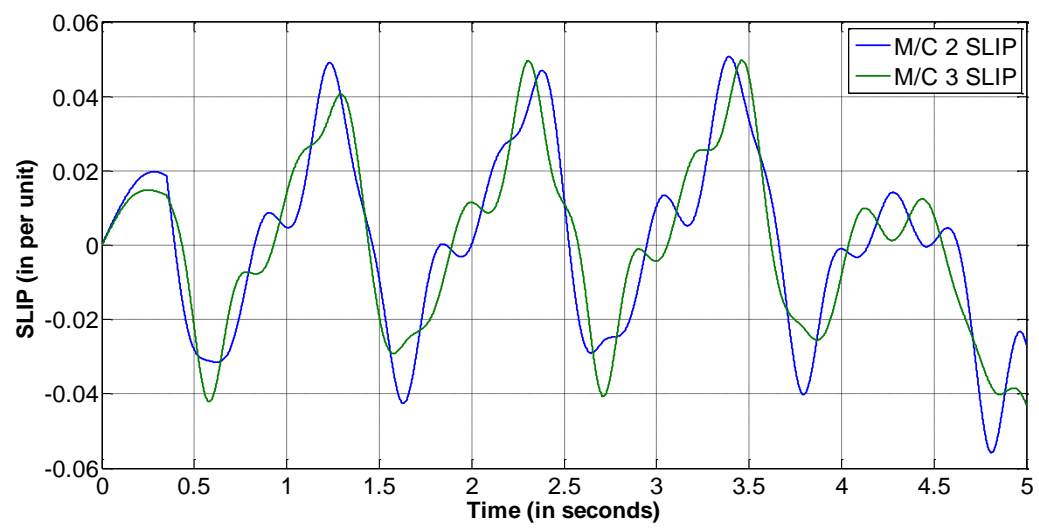

Figure 12. Speed Variation without DI

\subsubsection{With $75 \%$ Line Compensation}

Figure 13 depicts the variation of rotor angles of machines 2 and 3 . The system is stable as it is very clear from the figure. The slip variation is plotted in Figure 14.

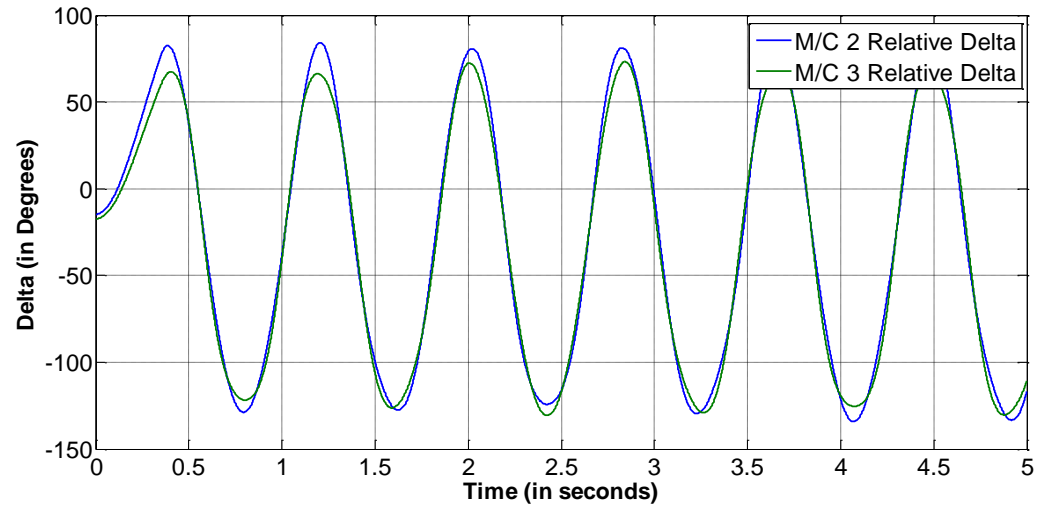

Figure 13. Delta Variation with 75\% Line Compensation

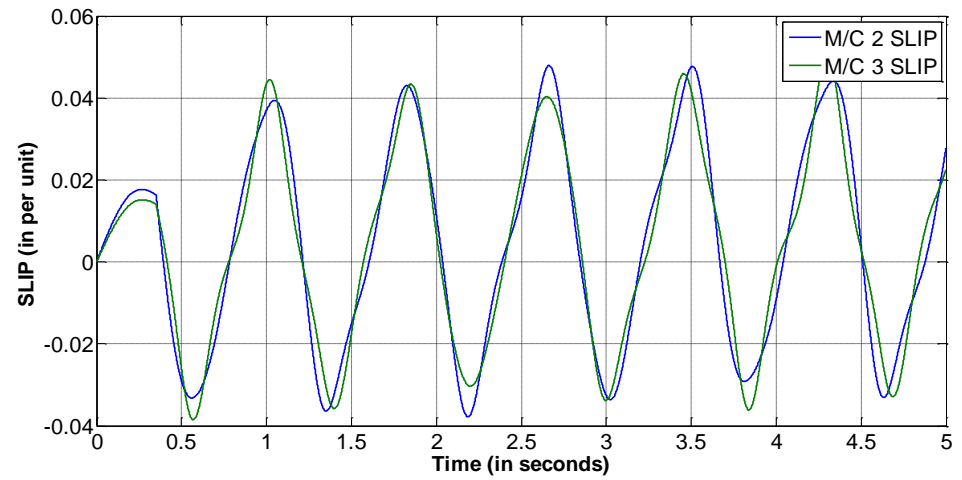

Figure 14. Slip Variation with $75 \%$ Line Compensation

\subsubsection{With DI Technique}

When fault clearing time is $0.35 \mathrm{sec}$, the variation of delta with DI technique, is plotted in Figure 15. The oscillations are damped in nature. The speed variations of the two machines (2 and 3 ) are shown in Figure 16. The performance is definitely better with DI technique. 


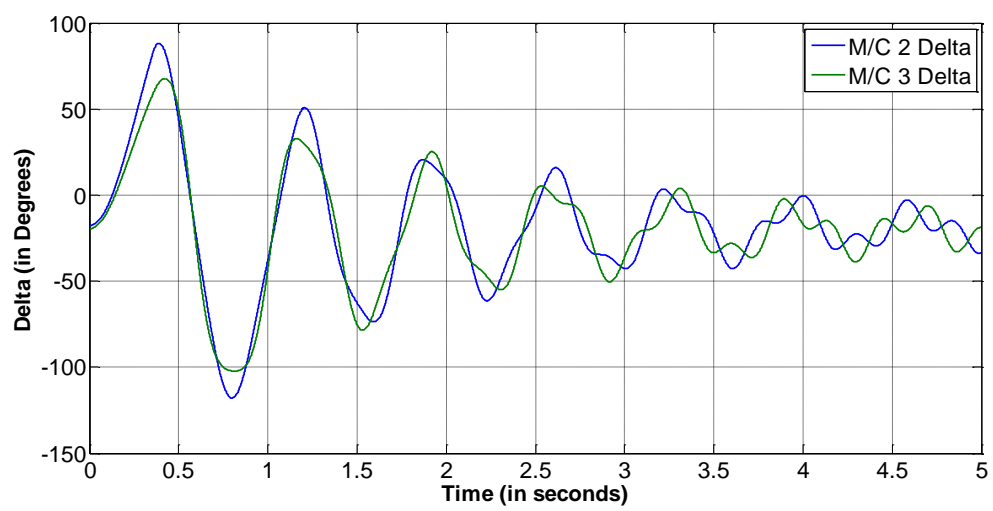

Figure 15. Delta Variation with DI technique

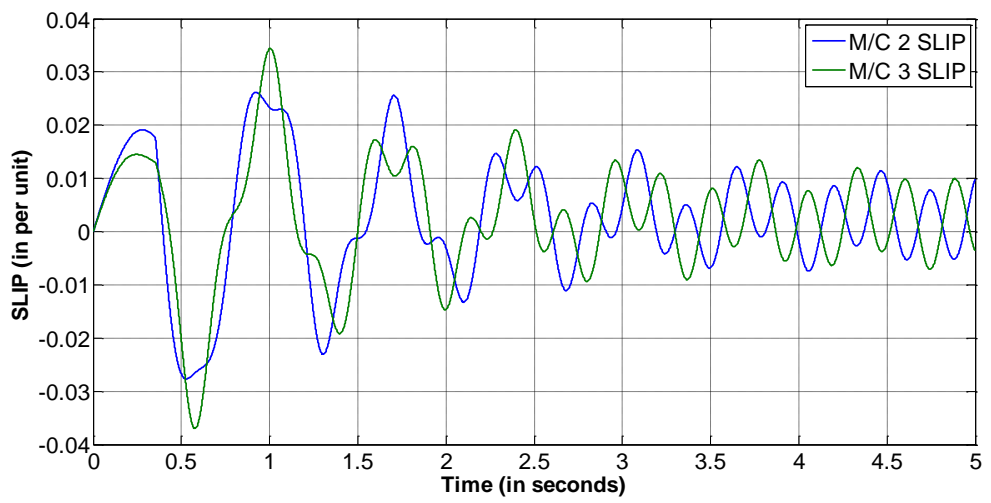

Figure 16. Speed Variation with DI technique

\subsection{Critical Clearing Time and maximum Loading at buses}

With clearing time as $0.2 \mathrm{sec}$, the loading was increased. The variation of the speeds of the generators, connected to all the three buses, was observed. The time when any one of the speeds becomes unstable was recorded. Similarly the rotor angle variations were also observed. With the fixed loading, the clearing time is increased till the system becomes unstable and the time is noted down.

Table 4. CCT and Maximum Loading

\begin{tabular}{lccc}
\hline \multicolumn{1}{c}{ Attribute } & Without TCSC & With 75\% Compensation & With TCSC \\
\hline Critical Clearing time(in sec) & $0.34 \mathrm{sec}$ & $0.4 \mathrm{Second}$ & $1.2 \mathrm{sec}$ \\
Maximum Loading at bus 4 & $76 \mathrm{MW}$ & $90 \mathrm{MW}$ & $96 \mathrm{MW}$ \\
Maximum loading at bus 5 & $81 \mathrm{MW}$ & $85 \mathrm{MW}$ & $97.5 \mathrm{MW}$ \\
\hline
\end{tabular}

\section{CONCLUSION}

For both the test systems considered, it is found that the, results with DI technique is better than that without DI technique and also when the line is $75 \%$ compensated. The DI technique was realized through TCSC and only $25 \%$ of the line reactance was varied through TCSC. For test system 1 , case 1 confirms that the unstable system can be stabilized with the help of DI technique. The critical clearing time is increased from 0.3 second to 0.36 second when the line is $75 \%$ compensated and increased to 0.338 when DI technique is used. Loading can be increased at buses 3, 4 and 5 as is depicted in Table 2.

For test system 2, case 1 reiterates that the stability of the system can be improved when $75 \%$ line compensation is used and further improved when DI technique is used. The critical clearing time is increased from 0.34 second 0.4 second when $75 \%$ line compensation is used and it is increased to 1.2 seconds when DI technique is used. Loading can be increased at buses 4 and 5 which is tabulated in Table 4 . Hence it is proved that when DI technique is used, the damping is improved, the systems' stability improves, the critical clearing time is increased and the maximum loading at various buses can be increased. 


\section{REFERENCES}

[1] K. R. Padiyar, "Structure Preserving Energy Functions in Power Systems: Theory And Applications," CRC Press, Taylor \& Francis Group, 2013.

[2] K. R. Padiyar and K. U. Rao, "Structure Preserving Energy Function and Stability Boundary - Recent Developments," Presented at the $8^{\text {th }}$ National Power Systems Conference, I.I.T. Delhi, 1994.

[3] K. S. Chandrashekar and D. J. Hill, "Cutset stability criterion for power system using a structure preserving model," Intl. Journal of Electrical Power and Energy systems, vol/issue: 8(3), pp. 146-157, 1986.

[4] G. S. Rao and A. Srujana, "Transient Stability Improvement of Multi-machine Power System Using Fuzzy Controlled TCSC," International Journal of Advancements in Research \& Technology, vol/issue: 1(2), 2012.

[5] M. A. Baseer, "Transient Stability Improvement of Multi-machine Power System using Fuzzy Controlled TCSC," IOSR Journal of Electrical and Electronics Engineering (IOSR-JEEE), vol/issue: 9(1), pp. 28-40, 2014.

[6] P. Taneja and Lakhwinder, "Stability Improvement of Multi-Machine Using STATCOM," International Journal of Advanced Research in EEIE, vol/issue: 2(8), pp. 3889-3894, 2013.

[7] L. Mathew and S. Chatterji, "Transient Stability Analysis of Multi-Machine System Equipped with Hybrid Power Flow Controller," IJCEM, vol/issue: 15(4), pp. 1-10, 2012.

[8] G. A. Ajenikoko and A. A. Olaomi, "A Model for Assessment of Transient Stability of Electrical Power System," International Journal of Electrical and Computer Engineering (IJECE), vol/issue: 4(4), pp. 498-511, 2014.

[9] K. Joshi and V. Chandrakar, "Transient Stability Improvement Using UPFC-SMES in a multi-machine Power System,” International Journal of Applied Power Engineering (IJAPE), vol/issue: 5(1), pp. 14-21, 2016.

[10] R. Padhi, et al., "Command Tacking in High Performance Aircrafts: A New Dynamic Inversion Design," 17th IFAC Symposium on Automatic Control in Aerospace, Touoluse, France, vol. 17, pp. 79 - 84, 2007.

[11] A. Tripathi and R. Padhi, "Robustness Study of a Dynamic Inversion Control Law for a High Performance Aircraft," Proceedings of the International Conference on Aerospace Science and Technology, India, 2008.

[12] A. Tripathi and K. U. Rao, "Dynamic Inversion Controller for Improving the Stability and Damping In Single Machine Infinite Bus System," 8th Control Instrumentation and Systems International conference CISCON-2011, Manipal Institute of Technology, Manipal, India, 2011.

[13] A. Tripathi, et al., "Robustness Study of Dynamic Inversion Technique Used in Power System Stability Analysis," IEEE Intl. Conference on Circuits Power and Computing Technologies, Nagarcoil, India, pp. 435-438, 2013.

[14] A. Tripathi, et al., "Dynamic Inversion Technique for TCSC under Varying Voltage Conditions," Intl. conference on Power \& Energy Systems: Towards Sustainable Energy, PESTSE 2014, pp. 1-4, 2014.

[15] G. W. Stag and A. H. E. Abiad, "Computer Methods in Power System Analysis," McGraw-Hill Publications, 1987. 